This paper is published in the open archive of Mid Sweden University

DIVA http://miun.diva-portal.org

with permission of the publisher

Citation for the peer-reviewed published paper:

Forsström J, Wågberg L. Influence of different deinking efficiency of waterbased flexographic ink from model cellulose surfaces and sheets. Nordic Pulp and Paper Research Journal. 2004;19(2):250-256.

URL to article at publishers site:

http://dx.doi.org/10.3183/NPPRJ-2004-19-02-p250-256 


\title{
Influence of different storage conditions on deinking efficiency of waterbased flexographic ink from model cellulose surfaces and sheets
}

\author{
Jennie Forsström, Fibre Science and Communication Network, Midsweden University, Lars Wågberg, KTH, Royal Institute of Technology, Sweden
}

KEYWORDS: Ageing, Brightness, Deinking, Dissolving pulps, Flexography, Image analysis, Inks, Surfaces, Thin films

\begin{abstract}
SUMMARY: The influence of UV-light, temperature, atmospheric environment and storage time on the ink detachment of water-based flexographic ink printed on model cellulose surfaces was investigated using an impinging jet cell equipment. The printed surfaces were deinked using a $\mathrm{NaOH}$ solution $(\mathrm{pH}=10)$ and the deinking process was monitored using a microscope equipped with a CCD camera. Images were collected at different time intervals during the detachment process and image analysis was used to quantify the ink detachment from the surface. Hand sheets, (the same pulp as used for model surface preparation) were also printed and stored under the same conditions, after which they were reslushed and deinked. The deinking efficiency of the recycled sheets was evaluated using brightness and ERIC (Effective Residual Ink Concentration) values. It was shown that UV-light had a negative effect on ink detachment both from the model cellulose surfaces and from the hand sheets. At storage temperatures of $55^{\circ} \mathrm{C}$, (dark conditions were used) a large negative effect was observed for the cellulose surfaces while only a small effect on the ink detachment could be seen for the hand sheets. Ink detachment from the hand sheets became more difficult when increasing the storage temperature above $55^{\circ} \mathrm{C}$, as detected as a decrease in brightness of the recycled and deinked sheets. A further increase in the storage temperature to $105^{\circ} \mathrm{C}$ gave poorer ink detachment efficiency than storage under UV-light for the hand sheets. Air had a more negative effect on ink detachment than nitrogen.
\end{abstract}

ADDRESS OF THE AUTHORS: Jennie Forsström (jenfor@kth.se) and Lars Wågberg (wagberg@pmt.kth.se): Department of Fibre and Polymer Technology, Division of Fibre Technology, KTH, SE-100 44 Stockholm, Sweden.

Corresponding author: Jennie Forsström.

Paper recycling today constitutes more than one third of the fibrous raw material required by the paper industry worldwide. For many years, the main part of the collected wastepaper has been used for making unbleached packaging paper and paperboard. However, a smaller but all the time increasing portion is now being treated for the removal of contaminants such as inks, stickies and resins so that it can be used for tissue products and printing and writing papers (Andreasson, Wågberg 2001; Dey et al. 1995). The deinking plant must deal with a wide variety of paper types, ink types and printing techniques with some papers relatively easy to deink while others can create problems. The deinking plant is expected to produce a pulp of consistently high quality from this mixture of recovered papers. Unfortunately, this ambitious goal is sometimes difficult to achieve. Some residual ink particles are always present in deinked pulp. This is particularly true when the deinking process is not designed or optimised for handling a particular ink.

The efficiency of the deinking process depends on several factors such as ink characteristics and paper surface properties. Ink properties such as pigment size and type of solvent used will strongly influence deinkability (Rangamannar et al. 1992; Wasilewski 1987). Paper and fibre surface properties are important since they affect the ease of ink detachment. Inks printed on coated paper surfaces detach more easily than inks printed directly on uncoated paper surfaces (Sjöström, Calmell 1997). Printing conditions and fibre properties are other factors that will affect the deinking efficiency (Sjöström, Calmell 1997; Shrinath et al. 1991; Miller, Xiansheng 1997).

There are currently two principal conventional deinking methods in use. The flotation method works well in cases where offset printed papers are being recycled, but the method is not suitable for flexographic printed papers. Removal of freshly printed flexographic ink is, under the usual deinking conditions, very easy but flotation of the removed ink particles is very difficult. The reason for this is that they are too small and hydrophilic which means that they will not attach to the collectors in the flotation process. Current recycling processes therefore incorporate aggressive washing stages to successfully remove flexographic inks. The yield losses associated with such washing stages are often economically unacceptable. Deinking processes and fundamentals have been reviewed recently elsewhere and will not be given here (Barassi, Welsford 1992; Heindel 1999; Kemper 1999; Fergusson 1992a; Fergusson 1992b).

In order to develop the most efficient deinking system it is important to study, in detail, each part of the deinking process to find the critical factors in each step. Such studies can be challenging due to the mixture of different fibres, additives and seasonal variations of the raw material of secondary fibres. It is important to find a reliable model system that represents each part in the deinking process and is well-controlled without any unwanted or unknown variations. Such a model system will be very useful in the development of new chemicals and procedures since several variables can be tested in a short period of time.

Different model systems are currently being used to study the different parts in the deinking process. Rao and Kuys (1995) investigated the detachment of offset news ink from printed model papers after natural and artificial 
ageing. The artificial ageing of offset printed papers, by a sunlamp, causes a large difference in the deinkability. This poor deinkability of aged offset ink and paper has been described as an oxidative process by which the chemical interaction between the ink and paper is increased, negatively affecting the deinkability (Rao, Kuys 1995; Castro et al. 1996; Rosinski 1995). Aspler (1993) suggested that chemical interactions between newsprint ink and the substrate is of limited importance. These authors explained the oil-paper and water-paper interaction using a traditional approach in which paper is considered a porous substrate and the ink setting is described by the Lucas-Washburn equation. The final interaction is then determined by the ink chemistry and the penetration depth of the ink . Borchardt et al. (1993) described a model system based on 1H-NMR imageing where the ink detachment is followed in situ. It was stated that this method provides a rapid screening tool for predicting the effectiveness of deinking surfactants. However, the NMR imageing equipment is expensive and still rather complicated to use effectively. A new method which uses model cellulose surfaces to study the mechanism behind ink detachment from cellulose surfaces was recently developed (Andreasson, Wågberg 2001). It was shown that the washing process in fact removes flexographic ink whereas removal of offset ink requires a certain hydrodynamic shear in combination with swelling of the model cellulose surface. It was also suggested that flexographic ink ages under different conditions such as air and UV-light. Sain and Daneault (1996) investigated the ageing of flexographic ink. Flexographic ink and binders were aged at $105{ }^{\circ} \mathrm{C}$. It was claimed that the presence of univalent metal ions in a sulphopolyester-based flexographic ink inhibits ageing (cross-linking) of acrylic binders. The effect of different surfactants on the deinking process has also been investigated previously (Gecol et al. 2001; Mørbak et al. 1999; Rao, Stenius 1998).

The purpose of the present study was to further use the new method developed by Andreasson and Wågberg (2001) for studies of ink detachment from model cellulose surfaces and to clarify how different storage conditions affect the detachment of flexographic ink. This new method uses printed model surfaces, an impinging jet set-up for treatment of model surfaces and a CCD camera attached to a microscope which makes image analysis of collected images possible. Ink detachment from hand sheets, from the same batch of fibres that were used for preparation of the model cellulose surfaces, was also investigated in order to compare the model studies with studies on actual paper sheets.

\section{Experimental}

\section{Materials}

Model surfaces. Model cellulose surfaces were prepared by coating a transparent glass slide with a solution of dissolved cellulose. A round glass slide (diameter $=19$ $\mathrm{mm}$ and thickness $=1.2 \mathrm{~mm}$ ) was placed in methanol and treated in an ultrasonic bath (Transonic T 570, 50/60 Hz, Tamro Medlab, Gothenburg, Sweden) for 30 minutes. The glass slide was then rinsed and placed in deionised water and treated in the ultrasonic bath for a further 30 minutes. The glass slide was then allowed to dry in a desiccator before use and if deemed necessary was further cleaned using nitrogen gas. The glass slide was then pre-coated with an anchoring layer of $0.1 \mathrm{~g} / \mathrm{l}$ G-PAM (glyoxylated-polyacrylamide), solution for 15 minutes after which it was dipped into deionised water and dried with nitrogen gas.

The preparation of the cellulose solution has been described in detail previously (Gunnars et al. 2002) and the procedure is therefore only briefly described here. Cellulose (0.5 g., dissolving pulp, Domsjö Fabriker AB, Sweden) was torn into small pieces and placed in a glass beaker. $25 \mathrm{~g}$ NMMO (N-Methylmorpholine N-oxide, 25 $\mathrm{wt} \%$ solution in water, Aldrich) was added and the suspension was heated to $115^{\circ} \mathrm{C}$ in order to dissolve the cellulose. The clear yellow solution was diluted with DMSO (25 g, Dimethylsulfoxide, pro analyse, Aldrich) and the solution was stirred for 30 minutes. The temperature was maintained at $115{ }^{\circ} \mathrm{C}$ during the preparation of the cellulose films.

The pre-coated glass slide was placed on a spin coater and the surface was covered with $350 \mu$ of the cellulose solution. A thin, transparent film of cellulose was formed on the slide by spinning at $3000 \mathrm{rpm}$ for 30 seconds. The cellulose coated slide was then placed in deionised water for 4 hours and the water was changed once during this time. Finally the surfaces were dried and stored in a desiccator before use.

Sheet preparation. Sheets, with a grammage of 60 $\mathrm{g} / \mathrm{m}^{2}$, were prepared from dissolving pulp (dissolving pulp, Domsjö Fabriker AB, Sweden) according to ISO 5269-2:1998.

Ink characteristics. The flexographic ink used in this study was 82 Aquajet black ink ( 15 wt $\%$ Pigment (CI PB 07), 25 wt $\%$ Acrylate (Joncryl 90), $\sim 2$ wt $\%$ Defoamer, $\sim 1.5 \mathrm{wt} \%$ Poly Ethylene wax) from A/S Torda Fabrikker, Lierstranda Norway.

Joncryl 90 is a styrene-acrylic copolymer emulsion commonly used in water-based inks and has the following specifications; Mol. Weight (wt.av.) $>200000$, Viscosity $\left(25^{\circ} \mathrm{C}\right) 260 \mathrm{mPa} . \mathrm{s}, \mathrm{Tg} 110^{\circ} \mathrm{C}(50-60 \mathrm{wt} \%$ Deionised water (CAS\# 7732-18-5), 40 - 45 wt $\%$ Styrene acrylic latex, 2 - $5 \mathrm{wt} \%$ Ammonium hydroxide, $28 \%$ (CAS\# 1336-21-6).

\section{Method}

Printing technique. Flexographic ink (rastered pattern covering approximately $35 \%$ of the model surface) was printed both onto the cellulose surfaces and the hand sheets using an IGT Printability Tester F1, IGT, Amsterdam, Netherlands (Anilox force $75 \mathrm{~N}$, Printing force $125 \mathrm{~N}$, Speed $0.30 \mathrm{~m} / \mathrm{s}$ ).

Storage procedure. The printed cellulose surfaces and hand sheets were stored under controlled conditions in a special storage equipment, Fig 1 .

Storage time was 1, 4 and 10 days and three parameters, 


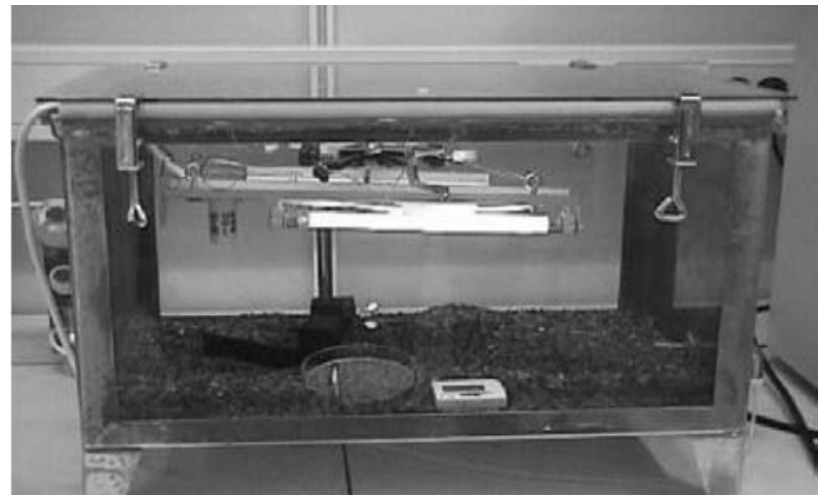

Fig 1. Storage equipment for ageing of printed cellulose surfaces and sheets. Light conditions, gas environment, temperature and storage time can be easily varied with this setup.

light condition, temperature and atmospheric environment were varied simultaneously according to a mixed full factorial design with constraints. The atmospheric environments were either nitrogen gas or air and the two different light conditions were either UV-light $(6 \mathrm{~W}, 254$ $365 \mathrm{~nm}$ ) or darkness. The temperatures were $15^{\circ} \mathrm{C}$ or $25^{\circ} \mathrm{C}$. Siccative was used to ensure low humidity. All experiments in the experimental design were performed in a random order. Surfaces and sheets were also stored for up to 2 weeks at higher temperatures ranging from $25^{\circ} \mathrm{C}$ up to $105^{\circ} \mathrm{C}$, during these experiments the atmospheric environment was air and no UV-light was used.

Ink detachment from cellulose surfaces. The ink detachment part of the deinking process was simulated by using an impinging jet cell set-up previously described in (Andreasson, Wågberg 2001). The printed surface was mounted in a liquid filled impinging jet cell and impinged with an alkaline water solution $(\mathrm{pH}=10)$ at room temperature. During all trials, the volumetric flow rate was kept at $1 \mathrm{ml} / \mathrm{s}$, which corresponds to an average velocity of $0.3 \mathrm{~cm} / \mathrm{s}$. The detachment of one dot of the rastered pattern was monitored and images of the ink detachment were collected every second and analysed by a software developed at SCA-Research (Sundsvall, Sweden). With this procedure, the collected images were converted to binary images (Fig 2) and a threshold limit was set for each image sequence. Ink was then assigned a value of 1 and the background a value of 0 .

The binary images were then analysed and the reduction of ink on the surface could be quantified as a function of time, an example of this is shown in Fig 3 .

From these results (Fig 3) a deinking efficiency number was defined that relates to how much ink that has been detached over the chosen washing time, in the present study 75 seconds, where a deinking efficiency number of 100 means that $100 \%$ of the ink had been detached and 0 means no ink detachment. The measured efficiency numbers were used as the response variable in the experimental design and further analysed using Partial Least Square, PLS (Vold et al. 1983). All experiments were performed four times and the result between the replicates did not differ more than $3 \%$. All calculations were performed using Matlab 6.1 (Comsol), Simca-P 8.0 (Umetrics, Sweden) and Modde 5.0

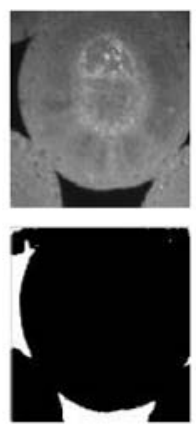

$0 \mathrm{~s}$

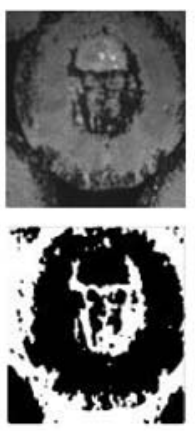

$5 \mathrm{~s}$
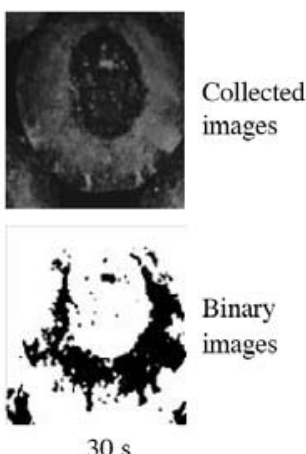

$30 \mathrm{~s}$
Fig 2. Collected images (upper row) are converted into binary images (lower row) using image analysis software developed at SCAResearch, Sundsvall, Sweden.

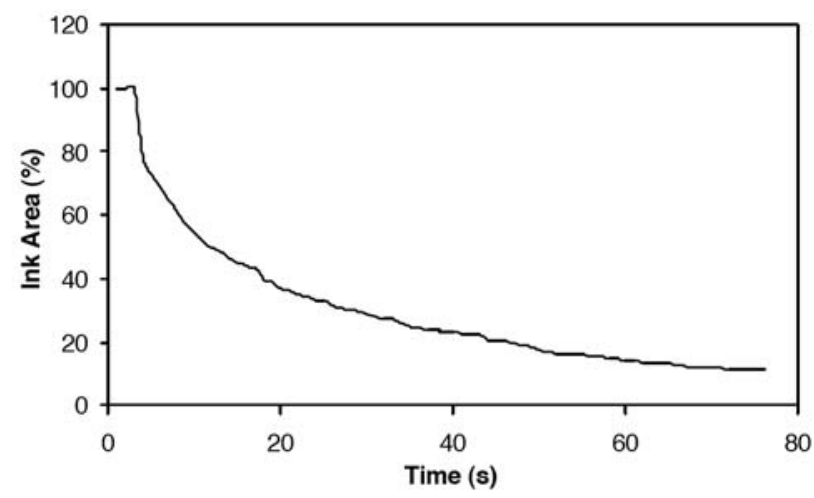

Fig 3. Ink area (\%) remaining on a printed model cellulose surface as a function of washing time (s). The deinking efficiency number is $88 \%$, that is $88 \%$ ink was detached from the surface.

(Umetrics, Sweden).

Ink detachment from sheets. 5 grams of printed sheets made from dissolving pulp were re-slushed in $250 \mathrm{ml}$ alkaline water solution $(\mathrm{pH}=10)$. The pulp was further diluted to 1.01 using alkaline water solution $(\mathrm{pH}=10)$ and washed/deinked in a Britt Dynamic Drainage Jar equipped with a $35 \mu \mathrm{m}$ screen (stirrer speed $1000 \mathrm{rpm}$ ). The pulp was then further washed/deinked with 31 of deionised water. Brightness sheets $\left(200 \mathrm{~g} / \mathrm{m}^{2}\right)$ were prepared from the reslushed and deinked pulp and from the reference pulp according to the SCAN CM 11:95 method. The brightness of the sheets was then analysed according to the SCAN P3: 93 on both sides of the sheet and ERIC (Effective Residual Ink Concentration) was analysed according to the method outlined by Jordan et al. (1994) and Carre et al. (1994) using Technibrite Micro TB-1C from Technidyne corporation (New Albany, Indiana, USA). All experiments were performed 4 times and the result between the replicates did not differ more than $5 \%$. Non-printed sheets were stored under the same storage conditions as the printed model cellulose surfaces and hand sheets. No difference in brightness or ERIC value could be detected, hence sheets stored at dark conditions, in air, at $25^{\circ} \mathrm{C}$ for 1 and 4 days were used as reference sheets.

FTIR (Fourier Transform Infra Red) - Spectroscopy. Ink varnish and spin coated cellulose were exposed to the same storage conditions as previously described and then analysed using ATR-FTIR in order to detect any chemical changes during storage. The IR measurements were performed with the aid of a Perkin Elmer Spectrum 2000 
FTIR equipped with a single reflection Attenuated Total Reflection (ATR) accessory from Specac Ltd. (Kent, England).

\section{Results}

\section{Deinking efficiency for cellulose surfaces}

In Figs 4 - 5 the effect of the different storage conditions on the ink detachment are shown. Fig 4 shows that storage under UV-light had a significant effect on the ink detachment compared to storage under dark conditions. After storing a printed model cellulose surface under UV light, at $15^{\circ} \mathrm{C}$ and nitrogen atmosphere for 1 day the amount of ink remaining on the surface after washing was $97 \%$, that is, almost no ink had been detached (efficiency number $=3$ ). For a printed cellulose surface stored under dark conditions, at $15^{\circ} \mathrm{C}$ and nitrogen atmosphere for 1 day the total amount of ink remaining on the surface after washing was $11 \%$, that is $89 \%$ had been detached (efficiency number $=89$ ).

The ink detachment efficiency from model cellulose surfaces was further evaluated using PLS. The different

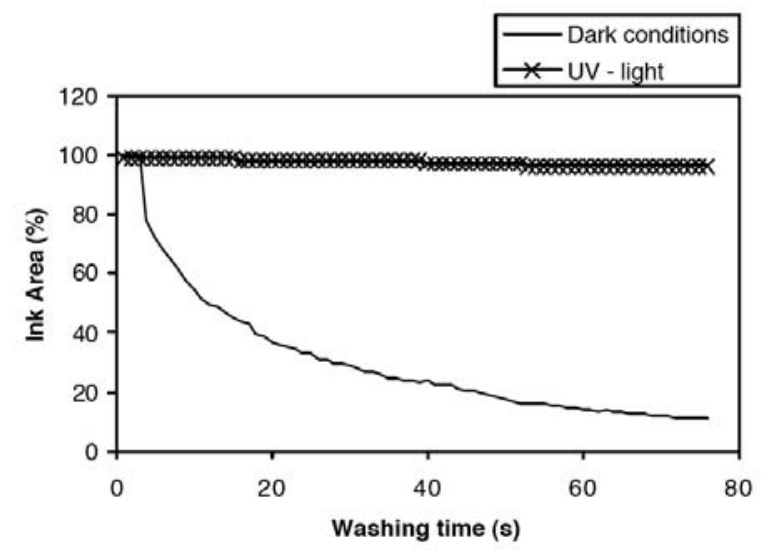

Fig 4. Ink area (\%) remaining on a deinked printed cellulose surface as a function of washing time (s). Deinking efficiency numbers are 0 $\%$ for surfaces stored under UV-light and $89 \%$ for surfaces stored under dark conditions.

storage conditions were varied according to a mixed full factorial experimental design with constraints and as response variable the efficiency number was used.

The PLS model resulted in $E q$ [1], in which y = efficiency number $(\%), \mathrm{x}_{1}=$ temperature $\left((\mathrm{C}), \mathrm{x}_{2}=\right.$ atmosphere, $\mathrm{x}_{3}=$ light conditions and $\mathrm{x}_{4}=$ storage time (days), which describes the ink detachment efficiency under the given conditions according to the experimental design.

$$
Y=100 *\left(0.47-0.004 x_{1}+0.019 x_{2}-0.27 x_{3}-0.025 x_{4}\right)
$$

As can be seen from $E q[1]$, the two major coefficients influencing deinking efficiency were a) light conditions and b) storage time. The temperature and the atmospheric environment, within the limits covered by the present investigation, seemed to have a minor effect on the ink detachment. To visualize the different storage conditions

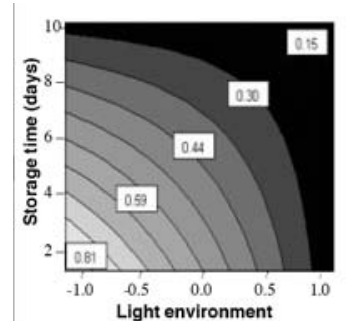

a)

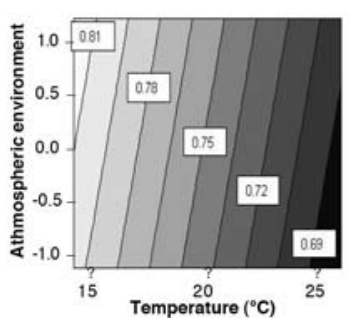

b)
Fig 5a. Deinking efficiency of model cellulose surfaces as a function of storage light $(-1=$ dark conditions, $+1=$ UV-light) and time (temperature was kept at $15^{\circ} \mathrm{C}$ and the atmospheric environment was nitrogen).

Figure 5b. Deinking efficiency of model cellulose surfaces as a function of atmospheric environment $(-1=$ air, $+1=$ nitrogen) and storage temperature (time was kept at 1 day and the light conditions were dark)

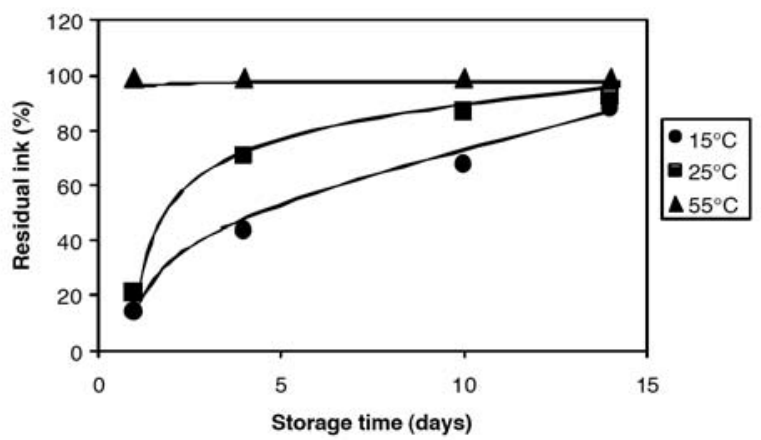

Fig 6. The amount of residual ink on model cellulose surfaces printed with flexographic water based ink as an effect of storage temperature and time. The light conditions were as dark as possible to minimize the effect of UV- light. The lines in the figure are mearly a guide to the eye.

effect on the ink detachment, response surfaces were plotted (Fig $5 a-b)$.

In the response surface shown in Fig $5 a$, it can be seen that in order to get as high a deinking efficiency as possible (over $80 \%$ ), the storage conditions should be as dark as possible (as close to -1 as possible). Furthermore, the storage time should be as short as possible. Samples should also be stored at a low temperature under nitrogen environment (as close to +1 as possible) in order to get a high ink detachment efficiency (Fig $5 b$ ). In this way the deinking efficiency increased from less than $15 \%$ to more than $80 \%$. As can be seen in Fig $5 \mathrm{~b}$, a temperature change from $15^{\circ} \mathrm{C}$ to $25^{\circ} \mathrm{C}$ influenced the deinking efficiency by only $12 \%$. Since storage temperature of real recycled paper often exceeds these values the temperature effect was further investigated by storing printed model cellulose surfaces at $15^{\circ} \mathrm{C}, 25^{\circ} \mathrm{C}$ and $55^{\circ} \mathrm{C}$ for up to 2 weeks. When raising the storage temperature from $15^{\circ} \mathrm{C}$ to $55^{\circ} \mathrm{C}$, there was a significant increase in the amount of ink present on the surface after the detachment process (Fig 6) even for short storage times.

As the storage time increased, surfaces stored at $15^{\circ} \mathrm{C}$ and $25^{\circ} \mathrm{C}$ became more difficult to deink. After 2 weeks of storage the amount of residual ink on the cellulose surface after detachment became more than $90 \%$. The figure also shows that cellulose surfaces stored at $55^{\circ} \mathrm{C}$ were not possible to deink at all. 


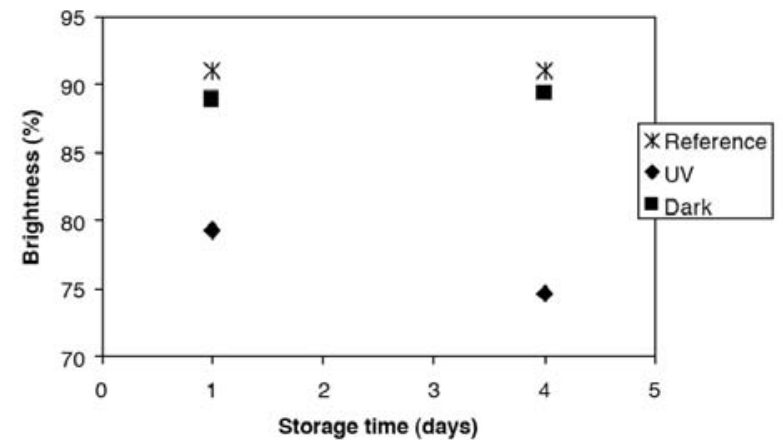

Fig 7. The effect of storage time and light conditions on brightness value of printed sheets, from dissolving pulp (temperature was kept at $\left.25^{\circ} \mathrm{C}\right)$.

\section{Deinking efficiency of hand sheets}

Fig 7 shows that storage under UV-light had a negative effect on deinking efficiency compared to storage under dark conditions. Reslushed and deinked sheets that were stored under UV-light for 4 days had $16 \%$ lower ISObrightness than the reference pulp. A small but significant decrease, $2 \%$, in brightness could be seen for reslushed and deinked sheets stored under dark conditions at $25^{\circ} \mathrm{C}$. Storage time had no effect on the brightness of surfaces stored under dark conditions whereas the sheets stored under UV irradiation showed a decreased brightness with increased storage time.

The effect of storage time and UV-light can also be seen in the ERIC values (Fig 8). This effect was similar to the brightness results. The ERIC values showed an increase from 114 up to 194 when increasing the storage time from 1 day to 4 days for sheets stored under UVlight.

As for the spin-coated cellulose surfaces, the temperature effect was further investigated by storing the printed sheets at different temperatures, $25^{\circ} \mathrm{C}, 55^{\circ} \mathrm{C}, 85^{\circ} \mathrm{C}$ and $105^{\circ} \mathrm{C}$, under dark conditions before reslushing and deinking. An increased temperature during storage had a large negative effect on the sheet brightness, especially for $85^{\circ} \mathrm{C}$ and $105^{\circ} \mathrm{C}$ (Fig 9). The reference sheet and the printed, reslushed and deinked sheets stored under dark conditions at $25^{\circ} \mathrm{C}$ had a brightness of $91 \%$ and $89 \%$, respectively, independent of storage time. Increasing the storage temperature to $55^{\circ} \mathrm{C}$ decreased the brightness of the deinked sheets to $88 \%$ and $87.5 \%$ for sheets stored for 1 and 4 days respectively. At a storage temperature of $85^{\circ} \mathrm{C}$, the storage time had a more significant effect on the brightness of the reslushed and deinked sheets. After 1 day of storage at $85^{\circ} \mathrm{C}$ the brightness was $85 \%$ and after 4 days of storage $68 \%$. Increasing the storage temperature further to $105^{\circ} \mathrm{C}$ caused a greater negative effect on the deinking efficiency and after 4 days of storage the brightness was as low as $57 \%$.

\section{Ink characterisation}

It has been suggested that an oxidative polymerisation of the ink resin is the reason for ageing of offset ink (Castro et al. 1996; Rosinski 1995; Aspler 1993). It has also been proposed that the difficulties to remove ink from aged paper are due to oxidation of hydroxyl-groups to carboxylic acids both in the fibres and in the ink (Castro et al.

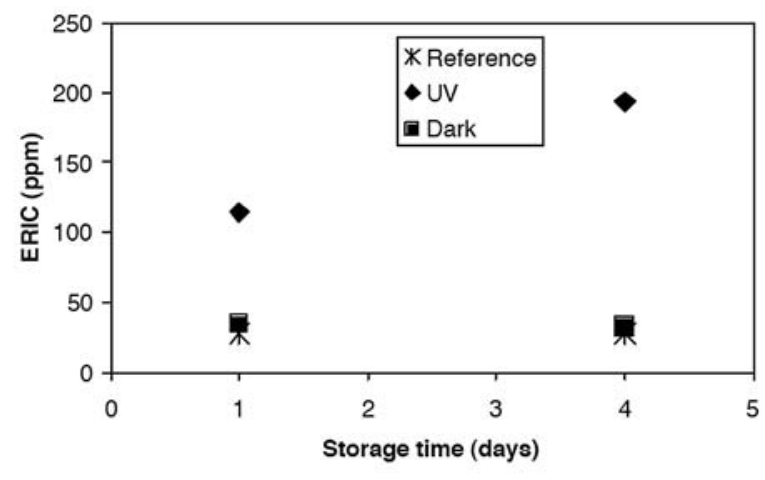

Fig 8. The effect of storage time and light conditions on ERIC value of printed sheets, from dissolving pulp (temperature was kept at $\left.25^{\circ} \mathrm{C}\right)$.

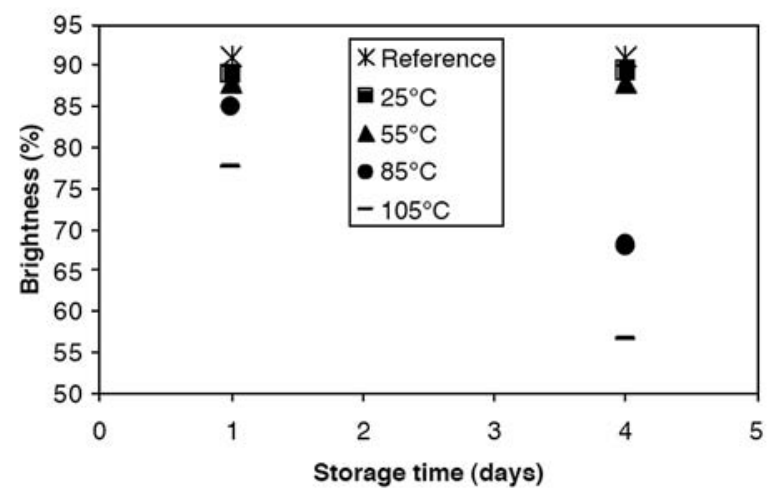

Fig 9. The effect of storage time and temperature on brightness value of printed sheets, from dissolving pulp, stored under dark conditions.

1996). It was therefore considered important to investigate if the detected changes in ink removal for the flexo printed surfaces could be traced back to changes in the chemistry of the ink. To study this, fresh and aged ink varnish was subjected to ATR-FTIR measurements. Spin coated cellulose, freshly prepared and aged, was also subjected to ATR-FTIR measurements. The results are shown in Figs 10 - 11.

The ATR-FTIR spectra for UV exposed spin-coated dissolved cellulose and non-UV exposed spin-coated dissolved cellulose are shown in Fig 10. No noticeable difference in chemical shift between the two spectra was observed.

This indicates that either no chemical changes occurred, over the chosen frequency range, or that the ATR-FTIR technique could not detect the chemical changes. The ATR-FTIR spectra for UV-exposed varnish and non-UV exposed varnish can be seen in Fig 11. As for the cellulose, no major chemical changes, over the chosen frequency range, could be detected.

\section{Discussion}

The effect of different storage conditions on deinking efficiency has previously been shown for offset ink (Rao, Kuys 1995). The chemical structure of offset ink is believed to change when exposed to different storage conditions. It is also believed that the ink-cellulose interaction changes as covalent bonds between the 


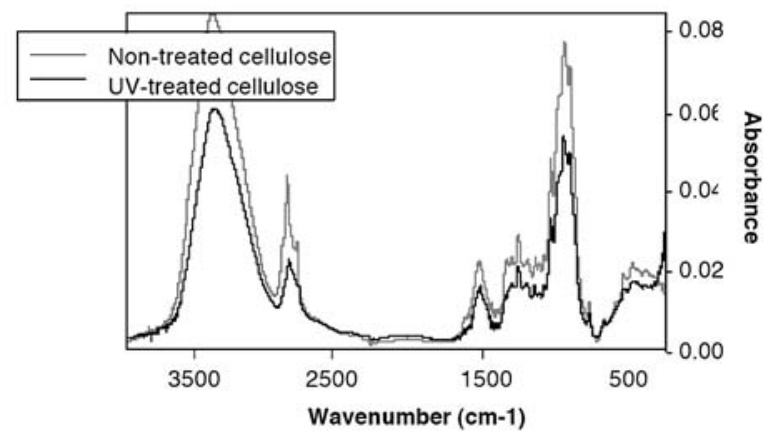

Fig 10. ATR-FTIR spectra of Non-treated and UV-treated spin-coated cellulose surfaces.

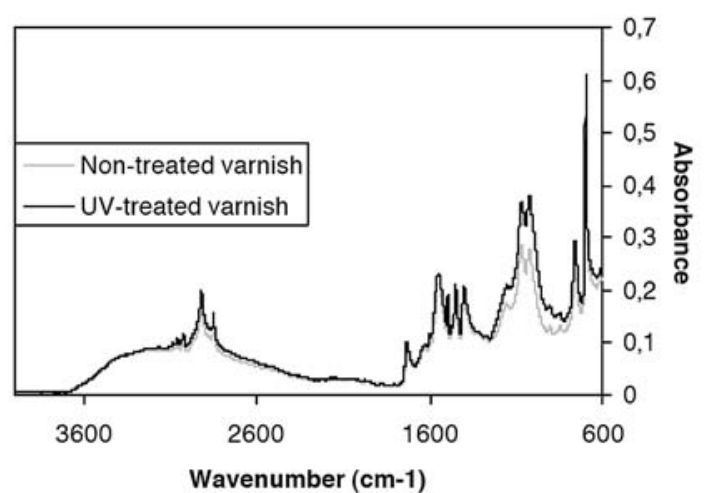

Fig 11. ATR-FTIR spectra of non-treated and UV-treated ink varnish.

carboxylic groups present in the ink and the fibre become possible. These chemical changes in ink and cellulose are believed to be the reason for the difficulties in ink detachment for offset inks. In this study it has been clearly shown that different storage conditions such as UV-light and high temperatures will affect the ink detachment of water based flexographic ink from different cellulose surfaces in a negative way. The changes in ink and ink-cellulose interaction at different storage conditions might be chemical or they might be physical. However, no chemical changes could be detected in the ATR-FTIR spectra after storage under UV-light for neither ink nor spin coated cellulose. It should be pointed out though, that since both the ink and the cellulose have high functionality, only a relatively few chemical binding sites are required to create strong bonding between ink and cellulose making the ink difficult to detach. Hence it is possible that an oxidative polymerisation reaction in the varnish-cellulose could have taken place but the ATR-FTIR could not detect them. It should also be pointed out that changing the atmospheric environment from oxygen to nitrogen had no major effect on the ink detachment. Hence it seems as if there are no chemical changes occurring due to oxidation reactions. This of course needs to be further investigated but the present results indicate that a physical change of the combined ink-cellulose system is the reason for the decreased ink detachment. Investigations regarding the change in the physical structure of the ink and the cellulose by AFM investigations are currently conducted in the laboratory of the authors.

The results also show that UV-light and storage temperature affected the ink detachment negatively for both spin coated cellulose surfaces and hand sheets, although the effect was slightly different. Ink detachment was hardly possible for printed model cellulose surfaces, stored in air under UV-light or at a storage temperature of $55^{\circ} \mathrm{C}$, even after only 1 day of storage. For printed hand sheets, UV-light and temperature decreased the ink detachment efficiency although it did not reach zero. This indicates that there is a difference in the ink detachment process between these surfaces even though the trends are very similar. This difference can naturally be traced back to the different physical structure of the surfaces but the differences in ink removal processes should also be kept in mind. The model cellulose surfaces are deinked using the impinging jet cell where the printed cellulose film is exposed to a stream of alkaline water at almost no shear. Furthermore, the stream hits the surface at the same place at the same impact angle all of the time. The hand sheets are reslushed and hyper washed which means that each fibre is exposed to a high shear and the alkaline water hits the fibre from numerous angles. The exposed surface is much larger for the fibre than for the cellulose film and thus enabling a higher deinking efficiency for the fibres. Further investigations are conducted also in this field.

\section{Conclusions}

The present work has shown that spin coated cellulose surfaces can be used as a model for cellulosic fibres in ink detachment studies. The impinging jet apparatus is an easy technique to study deinking and it provides a tool for studying the mechanism behind ink removal from model surfaces. The cellulose surfaces are easily made, the experiments are very fast, the surfaces can be easily modified and the wash liquid can be varied which provides a large variety in experiments that can be performed in a short period of time. It was also shown that storing the different surfaces under different light conditions, temperatures and storage times before deinking had a large effect on the deinking efficiency. UV-light, temperatures at and above $55^{\circ} \mathrm{C}$ and long storage time will all affect the deinking efficiency in a negative way for both spin coated cellulose surfaces and sheets made from dissolving pulp. It was also shown that no major chemical changes occurred in the ink varnish and the spin coated cellulose when stored under different conditions.

\section{Acknowledgement}

SCA $A B$ and the Fibre Science and Communication Network (FSCN) at Midsweden Univerisy is thanked for financial support and for laboratory help with preparation of the deinked printed sheets. Helge Viker, A/S Torda Fabrikker, is thanked for supplying the ink samples. Dr Shannon Notley is thanked for linguistic revision of the manuscript.

\section{Literature}

Andreasson, U. and Wågberg, L. (2001): Ink release from printed surfaces New methodology and initial insights to the true mechanism behind ink detach- 
ment, 12th Fundamental Research Symposium, Oxford, England, 1, 339. Aspler, J. S. (1993): Interactions of ink and water with paper surface in printing. Nordic Pulp Paper Res. J., 1, 68.

Barassi J. and Welsford, J. (1992): Latest development in deinking technology, Appita, 45(5), 308.

Borchardt, J. K., Tutunjian, P. N. and Prieto, N. E. (1993): Novel methods for laboratory evaluation of deinking surfactants, Tappi J., 76(7), 104.

Carre, B., Gallan, G. and Julien Saint Amand, F. (1994): Estimation of ink detachment and removal, Prog. Paper Rec., 4(1), 80.

Castro, C., Daneault, C. and Dorris G. M. (1996): Analysis of the accelerated thermal ageing of oil ink vehicles using isothermal thermogravimetry, J. Pulp Paper Sci. 22(10), 365.

Dey, A., Sarkar, D. and Basgupta, B K. (1995): The current state of paper recycling - A global review, IPPTA, 7(4), 1.

Fergusson, L. D. (1992a): Deinking chemistry: part 1, Tappi J., 75(7), 75

Fergusson, L. D. (1992b): Deinking chemistry: part 2, Tappi J., 75(8), 49.

Gecol, H., Scamehorn, J. F., Christian, S. D., Grady, B. P. and Riddell, F. (2001): Use of surfactants to remove water based inks from plastic films, Colloids Surfaces A: Physicochemical and Eng. Asp., 189, 55.

Gunnars, S., Wågberg, L. and Stuart, M. A. C. (2002): Model films of cellulose: 1. Method development and initial results, Cellulose, 9, 239.

Heindel, T. J. (1999): Fundamentals of flotation deinking. Tappi J., 82(3), 115.

Jordan, B. D. and Popson, S. J. (1994): Measuring the concentration of residual ink in recycled newsprint, J. Pulp Paper Sci., 20(6), 161.

Kemper, M. (1999): State of the art and new technologies in flotation deinking, Int. J. Mineral Proc., 56, 317.

Miller, J. D. and Xiansheng, N. (1997): The effect of ink types and printing pro- cesses on flotation deinking, Recycling Symp., Tappi Proc., 131

Mørbak, A. L., Degn, P. and Zimmermann, W. (1999): Deinking of soy bean oil based printed paper with lipases and neutral surfactant, J. Biotechnology, 67, 229. Rangamannar, G., Grube, G. and Karneth, A, M. (1992): Behaviour of waterbased flexographic inks in newsprint deinking, Tappi Pulping Conf., Tappi Proc., Boston, 3, 933.

Rao, R. and Kuys, K. (1995): Deinkability of aged paper, Appita, 601.

Rao, R. N. and Stenius, P. (1998): Mechanisms of ink release from model surfaces and fibre, J. Pulp Paper Sci., 24(6), 183.

Rosinski J. (1995): Ageing and deinking of soy printed newsprint, Prog. Paper Rec., 4(3), 55.

Sain, M. M. and Daneault, C. (1996): Thermo-oxidative behaviour of waterborne ink binders in the presence of monovalent metal ion, Polymer Degradation and Stability, 51, 67.

Shrinath, A., Szeuczak, J. T. and Bonen, I. J. (1991): A review of ink-removal techniques in current deinking technology, Tappi J., 74, 85.

Sjöström, L. and Calmell, A. (1997): Detachment of printing ink from different types of fibres, J. Pulp Paper Sci., 23(2), 67.

Vold, S., Martens, H. and Vold, H. (1983): Matrix Pencils, ed Ruhe A., Kågström B., Springer-Verlag, Heidelberg, 286.

Wasilewski, 0. (1987): Composition and chemistry of novel inks used in the newspaper industry and deinking, Tappi Pulping Conf., Tappi Proc., Washington, 1,25

Manuscript received December 19, 2003 Accpted March, 2004 